\title{
9 \\ A GESTÃO DO CONHECIMENTO E SUA RELAÇÃO COM A COMPETÊNCIA EM INFORMAÇÃO: PROPOSTA DE TRANSVERSALIDADE COMO SUBSÍDIOS INOVADORES PARA AS ORGANIZAÇÕES CONTEMPORÂNEAS
}

\author{
Beatriz Rosa Pinheiro dos Santos \\ Mestranda em Ciência da Informação pela Universidade Estadual Paulista \\ Júlio de Mesquita Filho, Brasil. \\ E-mail: pinheiro.santos@unesp.br \\ Camila Araújo dos Santos \\ Doutora em Ciência da Informação pela Universidade Estadual Paulista Júlio \\ de Mesquita Filho, Brasil. Professora da Faculdade Católica Paulista, Brasil. \\ E-mail: camilaar santos@hotmail.com \\ leda Pelógia Martins Damian \\ Doutora em Administração de Organizações pela Universidade de São \\ Paulo, Brasil. Professora Universidade de São Paulo, Brasil. \\ E-mail: iedapm@usp.br
}

\begin{abstract}
Resumo
A competência em informação é considerada um processo que auxilia no desenvolvimento de competências e habilidades que propicia a busca, recuperação, organização, avaliação e utilização da informação de maneira efetiva pelos usuários a fim de auxiliar nos processos decisórios de uma organização. Como o conhecimento é constituído por meio da informação utilizada e internalizada por um indivíduo até se transformar em conhecimento, se apoia na hipótese de que a competência em informação precisa estar atrelada a gestão do conhecimento com o intuito de potencializar ainda mais seus processos. Com isso, esta pesquisa possui o seguinte objetivo: inter-relacionar, em uma perspectiva transversal, processos da Gestão do Conhecimento com os princípios da Competência em Informação a fim de que essa competência possa oferecer subsídios estratégicos e inovadores para as organizações contemporâneas utilizarem o conhecimento tácito e o explícito a partir do uso inteligente e ético das informações. Para tanto, foi realizada uma pesquisa bibliográfica por se configurar em um estudo teórico elaborado a partir da leitura, análise e reflexão de materiais como artigos científicos, teses, dissertações, anais de eventos e livros. Como resultados e considerações finais, o estudo demonstrou que a transversalidade proposta tem por finalidade melhor compreender acerca das interfaces e possibilidades de inserção e desenvolvimento/aprimoramento da Competência em Informação nas ações de Gestão do Conhecimento em uma organização como proposta que vislumbra articular e mobilizar capacidades, habilidades, conhecimentos, atitudes, valores, competências e experiências que sustentam a postura de construção de conhecimento tácito e explícito do campo de atuação do gestor.
\end{abstract}

Palavras-chave: Gestão do conhecimento. Competência em informação. Organizações contemporâneas. Ética da informação.

Perspectivas em Gestão \& Conhecimento, João Pessoa, v. 8, número especial, p. 183-199, out. 2018. DOI: http://dx.doi.org/10.21714/2236-417X2018v8nep183

http://periodicos.ufpb.br/ojs2/index.php/pgc. ISSN: 2236-417X. Publicação sob Licença (cc) EY-NC-ND 


\title{
THE MANAGEMENT OF KNOWLEDGE AND ITS RELATIONSHIP WITH INFORMATION LITERACY: PROPOSAL FOR TRANSVERSALITY AS INNOVATIVE SUBSIDIES FOR CONTEMPORARY ORGANIZATIONS
}

\begin{abstract}
Information literacy is considered a process that assists in the development of skills and abilities that facilitates the search, recovery, organization, evaluation and use of information in an effective way by the users in order to assist in the decision processes of an organization. As knowledge is constituted through the information used and internalized by an individual until it becomes knowledge, it is based on the hypothesis that information literacy must be linked to knowledge management in order to further enhance its processes. This research has the following objective: to cross-relate, in a transversal perspective, Knowledge Management processes with the principles of Information literacy so that this competence can offer strategic and innovative subsidies for the contemporary organizations to use the knowledge tacit and explicit from the intelligent and ethical use of information. In order to do so, a bibliographical research was carried out to be configured in a theoretical study elaborated from the reading, analysis and reflection of materials such as scientific articles, theses, dissertations, annals of events and books. As results and final considerations, the study showed that the proposed transversality is intended to better understand the interfaces and possibilities of insertion and development / improvement of Information literacy in the actions of Knowledge Management in an organization as a proposal that aims to articulate and mobilize capacities, skills, knowledge, attitudes, values, skills and experiences that support the posture of tacit and explicit knowledge construction of the manager's field of activity.
\end{abstract}

Keywords: Knowledge management. Information literacy. Contemporary organizations. Ethics of information.

\section{INTRODUÇÃO}

Desde a Revolução Industrial, as instituições de ensino trabalham com o intuito de formar profissionais especializados para atender às demandas e irregularidades da economia, do mercado financeiro, da inovação e do mundo do trabalho. A sociedade e a ciência atual sentem necessidade e se esforçam para fazer a integração entre os campos de conhecimento (Ciências Humanas, Ciências Biológicas e Ciências Exatas e Ciências Sociais Aplicadas), entretanto o sistema de ensino brasileiro vai à contramão e ainda segue fragmentado e desarticulado com currículos escolares departamentalizados e incomunicáveis (PIRES, 1998).

Para Almeida Filho (1997), o conhecimento gerado nos sistemas educacionais está organizado e gerenciado de maneira fragmentada e não articulada, podendo ser comparado à organização do trabalho industrial, que transforma o indivíduo em um ser dividido e alienado.

Atualmente, o cenário social, político e econômico não operou mudanças significativas, visto que o estilo de vida e o modo cartesiano usado pelas pessoas ainda persiste e é isso que resulta na falta de sinergia e colaboração entre os campos disciplinares e indivíduos que neles estão inseridos, pois mesmo que mudanças neste quadro ocorram, as mesmas acontecem de maneira lenta (SILVA, 2017).

Visto a discussão exposta, com o intuito de colaborar cientificamente com a proposta pós-moderna de integração entre os campos do conhecimento, neste caso, a Administração e a Ciência da Informação, a discussão em questão possui por objetivo inter-relacionar, em uma perspectiva transversal, processos da Gestão do Conhecimento (GC) com os princípios da Competência em Informação (Colnfo) a fim de que essa competência possa oferecer subsídios estratégicos e inovadores para as organizações contemporâneas utilizarem o conhecimento tácito e o conhecimento explícito a partir do uso inteligente e ético das informações, visto que a informação configura-se na matéria-prima mais importante para a construção do

Perspectivas em Gestão \& Conhecimento, João Pessoa, v. 8, número especial, p. 183-199, out. 2018. 
conhecimento, logo, o uso efetivo da informação proporciona naturalmente o uso eficiente do conhecimento.

A GC é uma ferramenta imprescindível para os tempos atuais, pois é considerada um conjunto de estratégias voltada a criar, adquirir, compartilhar e utilizar os ativos do conhecimento que estabelecem apoio à solução de problemas e a tomada de decisão (VALENTIM, 2004).

A informação e o conhecimento são recursos organizacionais que ganham cada vez mais espaço e valor no âmbito empresarial, uma vez que propiciam a maximização dos processos de produção e um desenvolvimento organizacional efetivo (DIAS; BELLUZZO, 2003).

O conhecimento é construído por meio da internalização e da apropriação da informação pelo indivíduo, e dessa maneira, a informação passa a ser considerada insumo para a criação do conhecimento. Nesse processo de criação do conhecimento, as pessoas devem, primeiramente, manter e desenvolver um relacionamento competente com a informação que, consequentemente, irá auxiliar na construção de um conhecimento flexível e eficaz nas organizações. Nesse contexto, ser competente em informação envolve como característica um conjunto de comportamentos e habilidades relativas ao acesso e o uso da informação de maneira inteligente e ética (BELLUZZO; KOBAYASHI; FERES, 2004).

Com base nessas considerações, essa pesquisa se justifica por apresentar um caráter interdisciplinar envolvendo teorias do campo da Ciência da Informação $(\mathrm{Cl})$ e da Administração como a Competência em Informação e a Gestão do Conhecimento. Além disso, espera-se contribuir para o campo científico que possui visão pós-moderna e integrativa, como também para o gerenciamento das organizações contemporâneas.

\section{DESENVOLVIMENTO}

\subsection{Gestão do Conhecimento}

Para obter uma linha de raciocínio evolutiva sobre a construção do conhecimento, torna-se necessário compreender os conceitos de dados, informação e conhecimento, elementos complementares e dependentes uns dos outros.

De acordo com Hoffmann (2009), dado é informação bruta, primária, sozinha, sem propósito e significado. Os dados não conduzem à compreensão até que sejam estabelecidas relações entre eles, pois a partir dessas relações, se transformam em informação.

Para Drucker (1999), a informação é gerada por meio dos dados. É considerada dados interpretados, relacionados e dotados de relevância e propósito.

A informação se torna um recurso essencial nas organizações porque o seu cotidiano é dependente do processo de informação que se encontra presente no seio de todas as áreas do conhecimento, podendo ser usada em diversos contextos e situações. Dessa maneira, é considerada o insumo mais importante da produção humana (HOFFMANN, 2009).

A informação pode ser formal ou informal. "As informações formais são as que podem contar com um suporte e uma modalidade de estocagem ou armazenamento que the asseguram existência permanente" (HOFFMANN, 2009, p. 15). São originárias dos livros, filmes, internet, base de dados, revistas, jornais, bibliotecas, etc. Enquanto que a informação informal, segundo a autora, é proveniente das pessoas e se instaura por meio da socialização.

Segundo Hoffmann (2009), o conhecimento pode ser considerado o resultado da informação que é interpretada, estruturada e aplicada por alguém. Assim, a informação internalizada que se configura em uma ação, pode ser considerada conhecimento.

Sabbag (2007) afirma que "[...] conhecimento é informação processada que habilita à ação [...]". É por isso que o conhecimento é abordado como um insumo importante para as organizações contemporâneas, justamente porque os gestores começaram a entender que o conhecimento gera ação, e a qualidade do conhecimento, por sua vez, proporciona ações

Perspectivas em Gestão \& Conhecimento, João Pessoa, v. 8, número especial, p. 183-199, out. 2018. 
qualitativas nos processos decisórios e nos processos organizacionais. E a informação considerada insumo para a criação do conhecimento ganha valor e espaço nas organizações, bem como entre os funcionários, principais atores desses processos.

Davenport e Prusak (1998, p. 6) definem o conhecimento como

[...] uma mistura fluida de experiência condensada, valores, informação contextual e insight experimentado, a qual proporciona uma estrutura para a avaliação e incorporação de novas experiências e informações. Ele tem origem e é aplicado na mente dos conhecedores. Nas organizações, ele costuma estar embutido não só em documentos ou repositórios, mas também em rotinas, processos, práticas e normas organizacionais (DAVENPORT; PRUSAK, 1998, p.6).

Com isso, pode-se dizer que o conhecimento é uma informação que ganha personalidade. Isso porque uma única informação analisada por vinte pessoas diferentes resultará em vinte tipos de conhecimentos agregados a informação que foi analisada, pois cada indivíduo internalizou essa informação de maneira particular e única. Portanto, considera-se criativo o processo de internalização de uma informação e concomitantemente vantajoso, ao passo que apenas uma informação de qualidade pode gerar muitos tipos valiosos de conhecimento, visto que a informação é internalizada e interpretada por diferentes cognições, crenças, culturas, percepções e estado de emoção que cada indivíduo oferece. Nesse contexto, Setzer (2001) considera que o conhecimento passa a ser apontado como uma absorção interior e pessoal de uma informação que foi experimentada e utilizada por alguém.

O conhecimento tem sido um recurso muito desejado pelas organizações, pois é um insumo chave para as tomadas de decisões, previsões, planejamentos estratégicos, análises e avaliações no ambiente organizacional (SOFFNER, 2005). Assim como existem dois tipos de informação, formal e informação, também existem dois tipos de conhecimento: o tácito e o explícito. Segundo Nonaka e Takeuchi (1997), o primeiro é considerado pessoal, ligado à cultura e experiências pessoais, podendo ser transmitido pela socialização e convivência com outras pessoas; e o segundo é o conhecimento registrado e tangível, transmitido por meio da linguagem formal.

Entretanto, quando o conhecimento explícito é abordado e conceituado, alguns costumam confundi-lo com a informação formal, que por sua vez, também é originária do documento registrado. Assim, arrisca-se a dizer que não existe conhecimento tácito e explícito. Existe o conhecimento e suas transmissões tácitas e explícitas.

A gestão do conhecimento, para Hoffmann (2009), possui por objetivo a criação, o registro e o compartilhamento do capital intelectual das organizações, que inclui em sua definição a capacidade e o potencial intelectual dos funcionários.

Fundamentado na perspectiva da sociedade pós-moderna, onde a informação e o conhecimento ganham atribuições de valor, Malhotra (2001) explica que a gestão GC é uma área de estudos que auxilia no processo de adaptação e sobrevivência frente às mudanças que ocorrem no ambiente organizacional, além de incentivar a competência e a capacidade de inovação dos indivíduos geradores de conhecimento.

Maia (2003) acredita que a GC desempenha papel fundamental nos planejamentos estratégicos das organizações. Valentim (2004) define essa gestão como necessária para esse novo tempo, pautado pelo valor da informação, sendo considerada um conjunto de estratégias para criar, adquirir, compartilhar e utilizar os ativos de conhecimento que estabeleçam apoio para geração de novos conhecimentos, solução de problemas e tomada de decisão.

Uma das principais diretrizes da GC é o compartilhamento do conhecimento, responsável por capacitar os indivíduos a gerarem novos conhecimentos, isso porque 0

Perspectivas em Gestão \& Conhecimento, João Pessoa, v. 8, número especial, p. 183-199, out. 2018. 
compartilhamento é capaz de aprimorar as competências do indivíduo (CRAWFORD, 1994). Para Hoffmann (2009), a criação do conhecimento é o processo mais importante da gestão do conhecimento. Nessa linha de raciocínio, Nonaka e Takeuchi (1997) acreditam que esse processo de criação somente acontece se a organização estabelecer condições favoráveis como o incentivo à autonomia para criatividade, reflexão e comunicação dos funcionários, além de disposição para interagir com o ambiente externo à organização.

Davenport e Prusak (1998) afirmam que o conhecimento pode ser comparado a um sistema vivo, variável, que interage com o meio em que vive. Dessa maneira, a GC é responsável por tornar todo conhecimento passível de uso e de ação eficaz. Para conhecer mais a fundo as concepções e os processos da GC, alguns modelos voltados a essa gestão são apresentados.

\subsubsection{Modelos de Gestão do Conhecimento}

Assim como a informação é considerada objeto de pesquisa da $\mathrm{Cl}$, o conhecimento, não somente se encontra presente nela, mas em muitos outros campos do conhecimento que necessitam de informação e de conhecimento para sobreviver. Nesse sentindo, Stollenwerk (2001) afirma que a GC é objeto de uma diversidade de abordagens, definições e percepções.

Existem alguns autores como Wenger (1998), que acreditam que a GC é apenas um modismo gerencial da sociedade pós-moderna, que surge para auxílio das práticas gerenciais e que com o tempo desaparece. Todavia, dizer que a gestão do conhecimento é apenas um modismo passageiro é o mesmo que não confiar na existência do seu insumo: a informação, bem como não levar em consideração a capacidade cognitiva de apropriação da informação que possui o ser humano. A ciência pós-moderna necessita subsidiar e acreditar nos novos conceitos e nas novas reflexões que podem proporcionar quebras de paradigmas e ferramentas potenciais para a melhoria organizacional.

Na medida que existem muitas definições para o conceito de GC, também há uma diversidade de modelos que oferecem diretrizes e sustentação para se colocar em prática os processos relativos à essa gestão.

O modelo conceitual sobre gestão do conhecimento na organização de Terra (2001) apresenta sete dimensões sobre essa prática gerencial:

1) Visão e estratégia da alta gerência: a alta administração deve desempenhar papel fundamental na definição dos conhecimentos a serem focalizados, na construção de estratégias empresariais e na definição de metas;

2) Cultura Organizacional: esta dimensão está direcionada ao desenvolvimento de uma cultura organizacional voltada à inovação, à experimentação, ao aprendizado contínuo e à obtenção de resultados no longo prazo;

3) Estruturas organizacionais: construir estruturas organizacionais que incentive 0 trabalho de equipes multidisciplinares com alto grau de autonomia e o desenvolvimento de processos específicos que facilitem a geração, organização, disseminação e reutilização de conhecimentos organizacionais;

4) Políticas de recursos humanos: atribuir políticas de recursos humanos que estejam associadas à aquisição, à geração, à difusão e ao armazenamento de conhecimentos na empresa. Tais políticas devem auxiliar na atração e retenção de pessoas que venham contribuir para o compartilhamento de conhecimento na empresa;

5) Sistemas de informação e comunicação: aquisição de tecnologias de informação e comunicação (TIC) que auxiliem os processos de geração, compartilhamento e armazenamento de conhecimento nas organizações;

6) Mensuração de resultados: nesta dimensão, o foco está na compreensão de que o uso de indicadores relacionados à valorização do capital intelectual da empresa e a

Perspectivas em Gestão \& Conhecimento, João Pessoa, v. 8, número especial, p. 183-199, out. 2018. 
socialização tornaram-se mais do que necessários; e assim, é preciso promover ações para que esses indicadores sejam colocados em prática;

7) Aprendizado com o ambiente: proporcionar aos funcionários incentivo e engajamento para os processos de aprendizagem constante com o ambiente organizacional.

O modelo 'Processos essenciais na gestão do conhecimento' de Probst, Raub e Romhardt (2002), é baseado em um estudo dos seguintes processos pertencentes à GC organizacional:

1) Identificação do conhecimento: relacionado ao processo de análise e descrição do ambiente de conhecimento da empresa, assegurando auxílio para que os funcionários localizam o que precisam;

2) Aquisição de conhecimento: relacionada à importação de conhecimento advindo do processo de comunicação e relação com os clientes, fornecedores, concorrentes e parceiros da empresa;

3) Desenvolvimento do conhecimento: focalizado na prática de gerar novas habilidades, novos produtos, ideias melhores e processos mais eficientes;

4) Compartilhamento e distribuição do conhecimento: etapa que coloca como condição da empresa o desenvolvimento de práticas que transforme informações ou experiências isoladas dos funcionários em conhecimento que todos na organização possam utilizar, por meio do compartilhamento e distribuição desse conhecimento;

5) Utilização do conhecimento: consiste na prática de assegurar que os funcionários utilizem o conhecimento nas atividades diárias da empresa;

6) Retenção de conhecimento: relativo ao processo de estruturar e gerenciar o conhecimento, com o intuito de poder utilizá-lo futuramente e evitar a perda da memória organizacional.

Outro modelo relevante é de Davenport e Prusak (1998), que abordam quatro etapas para execução de uma gestão do conhecimento eficiente: (1) Geração: o conhecimento é gerado de forma intencional pelas pessoas; (2) Codificação e coordenação: o conhecimento é codificado e apresentado de maneira acessível e organizado às pessoas que dele necessitam; (3) Transferência: esta etapa é ativada pelo uso de ferramentas de tecnologia da informação; e (4) Utilização: o conhecimento transferido apresenta valor e relevância para o uso, mediante as necessidades das pessoas.

Bukowitz e Williams (2002) contemplam um modelo que tem por base a gestão do conhecimento no patamar dos processos tático e estratégico. Para cada um desses processos, os autores definiram diferentes etapas.

Para o processo tático têm-se as etapas (1) Obter, que destaca que as empresas devem utilizar as tecnologias de informação e comunicação a fim de conseguir selecionar a informação e o conhecimento necessário; (2) Utilizar, que incentiva a criação de soluções por meio da inovação e uso do conhecimento; (3) Aprender, considerada um desafio para as organizações, pois envolve processos diários de aprendizagem e até mesmo mudanças culturais a curto prazo que sejam potenciais para retornos positivos à longo prazo; e (4) Contribuir, que incentiva o trabalho em grupo, o compartilhamento do conhecimento e a socialização entre os funcionários, por meio de práticas que propiciem tempo e ambiente para essa interação.

Para o processo estratégico, observam-se as seguintes etapas: (1) Avaliação: nesta etapa, a organização necessita criar uma proposta de avaliação contínua do conhecimento dos funcionários, desse modo que o conhecimento passa a ser selecionado e resguardado para diferentes situações em que possa ser utilizado; (2) Construção e manutenção: objetiva que o conhecimento manterá a organização sempre competitiva, e na prática deve promover um

Perspectivas em Gestão \& Conhecimento, João Pessoa, v. 8, número especial, p. 183-199, out. 2018. 
relacionamento saudável e sinérgico entre os stakeholders da organização; e (3) Descarte: ressalta a importância das organizações desapegarem de ativos tangíveis, práticas e conhecimento que já não agregam valor às práticas e tomada de decisão no ambiente organizacional.

Torna-se evidente que, de forma geral, os modelos aqui contextualizados apresentam etapas e diretrizes focadas na aplicação da GC na prática organizacional. Cada etapa e cada diretriz demonstra que para serem colocadas em prática de maneira eficiente, é necessário que os gestores sejam competentes em informação, justamente porque o conhecimento caminha na dependência de informação bem gerenciada e de valor agregado.

\subsection{Competência em Informação (Colnfo)}

A Competência em Informação (Colnfo) é um "[...] processo de desenvolvimento/aprimoramento de competências, habilidades e atitudes que permite aos indivíduos buscarem, recuperarem, organizarem, avaliarem, comunicarem e utilizarem a informação de forma inteligente, ética, prática e crítica para a compreensão e intervenção de seu entorno, resolução de problemas e tomada de decisões para geração e construção de conhecimento" (SANTOS, 2017, p. 92).

A Colnfo engloba dimensões que a faz ser reconhecida como um processo holístico e integrado de competências de naturezas variadas. Morales (2000) disserta que a Colnfo tem uma grande globalidade no que se refere à diversidade de dimensões das competências, abarcando as instrumentais, de recursos, sócio estruturais, investigadoras, editoriais, tecnológicas e críticas, tais como se explana no Quadro 1.

Quadro 1 - Dimensões da Colnfo na perspectiva de Morales (2000)

\begin{tabular}{|c|c|}
\hline Dimensão & Competência \\
\hline Instrumental & $\begin{array}{l}\text { Capacidade para compreender e usar as ferramentas conceituais e } \\
\text { práticas das TIC, incluindo-se software, hardware e multimídia, que } \\
\text { são relevantes à educação e às áreas pessoais e profissionais. }\end{array}$ \\
\hline Recursos & $\begin{array}{l}\text { Habilidades para compreender a forma, o formato, os métodos de } \\
\text { localização e acesso aos recursos informacionais, especialmente } \\
\text { aqueles de redes expandidos diariamente. }\end{array}$ \\
\hline Sócio-estruturais & $\begin{array}{l}\text { Conhecer como a informação é socialmente situada e produzida. } \\
\text { Como se ajusta à vida dos grupos sociais (instituições e redes sociais } \\
\text { que criam e organizam informação e conhecimento) e os processos } \\
\text { sociais por meio dos quais é gerada. }\end{array}$ \\
\hline Investigadoras & $\begin{array}{l}\text { Capacidade para compreender e usar as ferramentas baseadas nas } \\
\text { tecnologias da informação relevantes para o trabalho de } \\
\text { pesquisadores. }\end{array}$ \\
\hline Editoriais & $\begin{array}{l}\text { Habilidade para dar forma e publicar eletronicamente pesquisas e } \\
\text { ideias em formatos impressos e eletrônicos (multimídia). }\end{array}$ \\
\hline Tecnológicas & $\begin{array}{l}\text { Habilidade para se adaptar continuamente às tecnologias emergentes, } \\
\text { para compreender, avaliar e fazer uso das contínuas inovações das TIC, } \\
\text { principalmente para tomar decisões inteligentes. }\end{array}$ \\
\hline Críticas & $\begin{array}{l}\text { Habilidade para avaliar criticamente as forças, fraquezas, intelectuais, } \\
\text { humanas e sociais, os limites e as potencialidades, os benefícios e os } \\
\text { custos das TIC. Para tanto, é preciso incluir diferentes perspectivas } \\
\text { nessa dimensão: histórica, filosófica, sociopolítica e cultural. }\end{array}$ \\
\hline
\end{tabular}

Fonte: Morales (2000, p. 38-39, tradução nossa).

Perspectivas em Gestão \& Conhecimento, João Pessoa, v. 8, número especial, p. 183-199, out. 2018. 
A influência da Colnfo no desenvolvimento socioeconômico tem sido reconhecida em âmbito internacional, pois tal competência opera em todos os níveis da atividade humana (educacional, social e profissional) (CATTS; LAU, 2008). No que concerne ao local de trabalho e ao desenvolvimento da GC, Catts e Lau (2008, p. 12-13) delineiam os seguintes indicadores de Colnfo:

- $\quad$ Necessidade de informação: consciência de que a solução de problemas no local de trabalho requer informação. A consciência da necessidade não é uma capacidade estática, mas algo que precisa ser questionado e testado pela busca de informações adicionais ou pela confirmação da exatidão da informação fornecida;

- Localizar e avaliar a qualidade da informação: é necessário adquirir habilidades não só para localizar, mas para avaliar fontes confiáveis. No local de trabalho, a informação pode ser localizada em manuais, em publicações de códigos de prática, em banco de dados, com indivíduos, etc.;

- $\quad$ Armazenar e recuperar informações: a capacidade para armazenar e recuperar informações para uso futuro;

- $\quad$ Fazer uso inteligente e ético da informação: a eficácia do uso da informação pode ser incluída em pesquisas de solução de problemas;

- Usar a informação para criar e compartilhar conhecimentos: possibilitar que pessoas criem e usem novos conhecimentos para a resolução de problemas.

As organizações devem fomentar iniciativas de implantação da Colnfo de modo a valorizar a informação como elemento primordial para a mudança de conduta nas ações dos gestores, visto que a falta dessa competência no ambiente de trabalho pode gerar consequências e problemas para a organização, tal como se aponta no Quadro 2.

Quadro 2 - Falta de competência em informação e suas consequências para o ambiente de trabalho

\begin{tabular}{|c|l|}
\hline $\begin{array}{c}\text { Exemplos de falta de } \\
\text { competência em informação no } \\
\text { ambiente de trabalho }\end{array}$ & \multicolumn{1}{|c|}{ Consequências / problemas } \\
\hline $\begin{array}{c}\text { Incapacidade do trabalhador em } \\
\text { determinar a natureza e a } \\
\text { extensão da informação de que } \\
\text { necessita }\end{array}$ & $\begin{array}{l}\text { Aumento de custo para a organização que paga acesso a muitos } \\
\text { bancos de dados e perde tempo para realizar a pesquisa sem } \\
\text { objetivo bem definido, recuperando informação excessiva ou } \\
\text { desnecessária. }\end{array}$ \\
\hline $\begin{array}{c}\text { Incapacidade de recuperar com } \\
\text { eficácia a informação e } \\
\text { desconhecimento da amplitude } \\
\text { dos recursos disponíveis }\end{array}$ & $\begin{array}{l}\text { Perda da qualidade de trabalho pela incapacidade de explorar } \\
\text { recursos informacionais dos sistemas de informação e desperdício } \\
\text { de tempo, buscando informação de qualidade inferior em fontes } \\
\text { inapropriadas. }\end{array}$ \\
\hline $\begin{array}{c}\text { Incapacidade de avaliar e filtrar as } \\
\text { informações }\end{array}$ & $\begin{array}{l}\text { Fornecimento de soluções impróprias ou erradas aos clientes, o } \\
\text { que pode causar perda de oportunidade de negócios. }\end{array}$ \\
\hline $\begin{array}{c}\text { Excesso de informações, caixa de } \\
\text { e-mail sobrecarregada, } \\
\text { incapacidade de explorar a } \\
\text { tecnologia para controlar a } \\
\text { informação. }\end{array}$ & $\begin{array}{l}\text { O empregado não consegue manejar o excesso de informação, } \\
\text { desperdiça tempo para realizar tarefas que podem ser feitas pela } \\
\text { tecnologia da informação e perde recursos informacionais } \\
\text { importantes. Isso reduz oportunidade de trabalhar em tarefas que } \\
\text { trazem resultados mais positivos. }\end{array}$ \\
\hline $\begin{array}{c}\text { Incapacidade de relacionar a } \\
\text { geração e o uso da informação a } \\
\text { um contexto mais amplo e de } \\
\text { avaliar os custos e os benefícios } \\
\text { da gerência da informação }\end{array}$ & $\begin{array}{l}\text { O trabalhador não conhece as informações existentes na } \\
\text { organização e cria as mesmas informações quando tem que } \\
\text { executar tarefas similares. Como não tem uma visão ampla da } \\
\text { informação, perde recursos construindo bases de dados múltiplas, } \\
\text { com conteúdo duplicado. Desperdiça recursos em bases de dados } \\
\text { que não trazem benefícios em longo prazo. }\end{array}$ \\
\hline Uso antiético da informação & \begin{tabular}{l} 
Esse comportamento antiético desencoraja o compartilhamento \\
\hline
\end{tabular} \\
\hline
\end{tabular}

Perspectivas em Gestão \& Conhecimento, João Pessoa, v. 8, número especial, p. 183-199, out. 2018. 
\begin{tabular}{|l|l|}
\hline & $\begin{array}{l}\text { da informação, reduz o moral dos trabalhadores, desanima a } \\
\text { inovação e a criatividade. }\end{array}$ \\
\hline
\end{tabular}

Fonte: Cheuk (2002 apud COELHO, 2011, p.176).

Catts e Lau (2008) destacam que as pessoas precisam mais do que apenas uma base de conhecimentos teóricos profissionais para lidar com as situações de trabalho, precisam de Colnfo para explorá-la, fazer conexões a outras bases de conhecimentos para utilizá-los de forma prática na compreensão de fatos, tomada de decisões e construção e socialização do conhecimento.

No Brasil, Belluzzo (2007) desenvolveu os padrões de Colnfo direcionados a nossa realidade, tal como seguem:

- $\quad$ Padrão 1: A pessoa competente em informação determina a natureza e a extensão da necessidade de informação;

- Padrão 2: A pessoa competente em informação acessa a informação necessária com efetividade;

- Padrão 3: A pessoa competente em informação avalia criticamente a informação e as suas fontes;

- $\quad$ Padrão 4: A pessoa competente em informação, individualmente ou como membro de um grupo, usa a informação com efetividade para alcançar um objetivo/obter um resultado;

Padrão 5: A pessoa competente em informação compreende as questões econômicas, legais e sociais da ambiência do uso da informação e acessa e usa a informação ética e legal.

A Colnfo finda a concepção de um agir estático, uma vez que trabalhar com a informação é uma atividade plural por decorrência das próprias peculiaridades do mundo informacional em que buscar, recuperar, organizar, avaliar, comunicar e usar a informação são ações dinâmicas, uma vez que todas as atividades estão embasadas por informações para a construção, geração e socialização de conhecimento.

\section{TRAJETÓRIA METODOLÓGICA}

A pesquisa em foco foi desenvolvida com base nos princípios teóricos de Marconi e Lakatos (2008), selecionando-se a modalidade de pesquisa bibliográfica por se configurar em um estudo teórico elaborado a partir da leitura, análise e reflexão de materiais como artigos científicos, teses, dissertações, anais de eventos e livros. A pesquisa bibliográfica compreende a identificação e o acesso à bibliografia já publicada e coloca o pesquisador em contato direto com tudo o que foi escrito ou dito sobre o tema de interesse (GIL, 2012).

A coleta de dados apoiou-se na reflexão e inter-relação do modelo de Gestão do Conhecimento de Probst, Raub e Romhardt (2002) e dos padrões nacionais de Competência em Informação de Belluzzo (2007) a fim de se propiciar subsídios gerenciais inovadores para as organizações contemporâneas.

\section{RESULTADOS E DISCUSSÕES}

O investimento no desenvolvimento/aprimoramento da Colnfo se faz necessário à medida que pode representar um diferencial competitivo e inovador visto que essa competência se encontra diretamente ligada à maneira como o sujeito lida de maneira crítica, inteligente, reflexiva, estratégica e ética com a informação para a construção, geração e

Perspectivas em Gestão \& Conhecimento, João Pessoa, v. 8, número especial, p. 183-199, out. 2018. 
compartilhamento de conhecimento significativo como fator de vantagem competitiva para as organizações.

Destaca-se que, na literatura há diversos modelos que demonstram as diretrizes e as etapas da GC nas organizações. Dentre eles, selecionou-se o modelo 'Processos essenciais na Gestão do Conhecimento' de Probst, Raub e Romhardt (2002) por não estar voltado, tão somente, ao nível tático e estratégico, mas a todos os indivíduos que compõem uma organização. No que concerne à Colnfo, selecionou-se os 'Padrões de Competência em Informação' de Belluzzo (2007), pois representa, em termos de características, a realidade brasileira.

Como resultado das abordagens descritas, se compreendeu ser elementar elaborar uma síntese que estabelece uma inter-relação entre o modelo de GC e os padrões de Colnfo com adaptações às características e princípios de uma organização em âmbito de transversalidade que só tem significado em uma perspectiva interdisciplinar do conhecimento.

A transversalidade proposta tem por finalidade melhor compreender as interfaces e possibilidades de inserção e desenvolvimento/aprimoramento da Colnfo nas ações de GC em uma organização como proposta que vislumbra articular e mobilizar capacidades, habilidades, conhecimentos, atitudes, valores, competências e experiências que sustentam a postura de construção de conhecimento tácito e explícito do campo de atuação do gestor.

A título de compreensão, expõem-se na primeira coluna as etapas do modelo "Processos essenciais na GC" de Probst, Raub e Romhardt (2002). Na segunda coluna há a apresentação dos "Padrões de Colnfo" de Belluzzo (2007) direcionados à consecução da GC pelos gestores, enquanto que na terceira coluna projeta-se a "Transversalidade da CoInfo à GC", cujos indicadores de desempenho e resultados desejáveis operacionalizam e dão suporte ao desenvolvimento da GC, tal como segue no Quadro 3.

Quadro 3 - Transversalidade entre os Padrões de Colnfo e os processos essenciais da GC nas organizações contemporâneas

\begin{tabular}{|c|c|c|}
\hline $\begin{array}{c}\text { Processos essenciais da } \\
\text { GC } \\
\end{array}$ & Padrões de Colnfo & $\begin{array}{c}\text { Indicadores de desempenho e resultados } \\
\text { desejáveis da Colnfo à GC } \\
\end{array}$ \\
\hline \multirow[t]{2}{*}{$\begin{array}{c}\text { 1) Identificação do } \\
\text { conhecimento: está } \\
\text { relacionado ao processo } \\
\text { de análise e descrição do } \\
\text { ambiente de } \\
\text { conhecimento da } \\
\text { empresa, assegurando } \\
\text { auxílio para que os } \\
\text { funcionários localizem o } \\
\text { que precisam. }\end{array}$} & $\begin{array}{l}\text { Padrão 1: } 0 \text { gestor } \\
\text { competente em informação } \\
\text { determina a natureza e a } \\
\text { extensão da necessidade de } \\
\text { informação. }\end{array}$ & $\begin{array}{l}\text { - Identifica um tópico de pesquisa ou } \\
\text { outra informação necessária sobre a } \\
\text { organização e o contexto que está } \\
\text { inserida; } \\
\text { - Usa fontes de informação gerais ou } \\
\text { específicas para aumentar seu } \\
\text { conhecimento sobre a organização e o } \\
\text { contexto que está inserida; } \\
\text { - Identifica e diferencia o valor e as } \\
\text { diferenças de potencialidades de fontes } \\
\text { em uma variedade de formatos de acordo } \\
\text { com as áreas de interesse da organização; } \\
\text { - Identifica o propósito e o tipo de } \\
\text { informação a que se destinam as fontes } \\
\text { de acordo com as áreas de interesse da } \\
\text { organização. }\end{array}$ \\
\hline & $\begin{array}{lll}\text { Padrão 2: } & \text { O gestor } \\
\text { competente em } & \text { informação } \\
\text { acessa a } & \text { informação } \\
\text { necessária com efetividade. }\end{array}$ & $\begin{array}{l}\text { - Diferencia as fontes de informação } \\
\text { reconhecendo o seu uso e a sua } \\
\text { importância para cada área específica da } \\
\text { organização; } \\
\text { - Identifica os tipos de informação } \\
\text { contidas em um sistema tradicional e os } \\
\text { tipos de fontes indexadas }\end{array}$ \\
\hline
\end{tabular}

Perspectivas em Gestão \& Conhecimento, João Pessoa, v. 8, número especial, p. 183-199, out. 2018. 


\begin{tabular}{|c|c|c|}
\hline & & $\begin{array}{l}\text { eletronicamente que sejam coerentes às } \\
\text { características e necessidades do } \\
\text { ambiente da organização; } \\
\text { - Seleciona apropriadamente os sistemas } \\
\text { de recuperação da informação para } \\
\text { pesquisar o problema baseado na } \\
\text { investigação da abrangência, conteúdo e } \\
\text { organização condizentes às características } \\
\text { do ambiente organizacional, como solicita } \\
\text { ajuda para pesquisar em diferentes } \\
\text { instrumentos como bases de dados, } \\
\text { fontes de referência, etc.; } \\
\text { - Identifica outros métodos de pesquisa } \\
\text { para obter informação necessária, os } \\
\text { quais podem não estar disponíveis por } \\
\text { meio dos sistemas de recuperação da } \\
\text { informação tradicional e eletrônico } \\
\text { (exemplo: consulta a especialistas, etc.); } \\
\text { - Usa vários sistemas de recuperação da } \\
\text { informação em uma variedade de } \\
\text { formatos (impressos e eletrônicos); } \\
\text {-Utiliza serviços online ou pessoas } \\
\text { especializadas disponíveis na instituição } \\
\text { para recuperar a informação necessária; } \\
\text { - Identifica lacunas na informação } \\
\text { necessária face aos resultados da } \\
\text { pesquisa; } \\
\text { - Revisa a estratégia de busca se for } \\
\text { necessário obter mais informação; } \\
\text { - Demonstra compreender como } \\
\text { organizar e tratar a informação obtida. }\end{array}$ \\
\hline & $\begin{array}{l}\text { Padrão 3: } \quad \text { O gestor } \\
\text { competente em informação } \\
\text { avalia criticamente a } \\
\text { informação e suas fontes. }\end{array}$ & $\begin{array}{l}\text { - Examina e compara a informação de } \\
\text { várias fontes para avaliar a sua } \\
\text { confiabilidade, validade, precisão, } \\
\text { autoridade, atualidade e ponto de vista } \\
\text { ou tendências do ambiente da } \\
\text { organização; } \\
\text { - Analisa a lógica da argumentação da } \\
\text { informação obtida, conferindo se é } \\
\text { coerente às necessidades da organização. }\end{array}$ \\
\hline $\begin{array}{c}\text { 2) Aquisição de } \\
\text { conhecimento: esta etapa } \\
\text { está relacionada à } \\
\text { importação de } \\
\text { conhecimento advindo do } \\
\text { processo de comunicação } \\
\text { e relação com os clientes, } \\
\text { fornecedores, } \\
\text { concorrentes e parceiros } \\
\text { da empresa. }\end{array}$ & $\begin{array}{l}\text { Padrão 2: O gestor } \\
\begin{array}{l}\text { 2ompetente em informação } \\
\text { acessa a informação } \\
\text { necessária com efetividade. }\end{array}\end{array}$ & $\begin{array}{l}\text { - Usa vários sistemas de recuperação da } \\
\text { informação em uma variedade de } \\
\text { formatos (impressos e eletrônicos); } \\
\text { - Utiliza vários esquemas de classificação } \\
\text { ou outros sistemas para localizar as } \\
\text { fontes de informação junto aos serviços } \\
\text { de informação; } \\
\text { - Utiliza serviços online ou pessoas } \\
\text { especializadas disponíveis na instituição } \\
\text { para recuperar a informação necessária. }\end{array}$ \\
\hline
\end{tabular}

Perspectivas em Gestão \& Conhecimento, João Pessoa, v. 8, número especial, p. 183-199, out. 2018. 


\begin{tabular}{|c|c|c|}
\hline & $\begin{array}{l}\text { Padrão 3: } \quad \text { O gestor } \\
\text { competente em informação } \\
\text { avalia criticamente a } \\
\text { informação e suas fontes. }\end{array}$ & $\begin{array}{l}\text { - Determina se a informação obtida é } \\
\text { suficiente e adequada ou se é necessário } \\
\text { obter mais informação; } \\
\text { - Compara a nova informação com o } \\
\text { conhecimento próprio e outras fontes } \\
\text { consideradas como autoridade no } \\
\text { assunto para conclusões. }\end{array}$ \\
\hline \multirow{3}{*}{$\begin{array}{l}\text { 3) Desenvolvimento do } \\
\text { conhecimento: está } \\
\text { focalizado na prática de } \\
\text { gerar novas habilidades, } \\
\text { novos produtos, ideias } \\
\text { melhores e processos } \\
\text { mais eficientes. }\end{array}$} & $\begin{array}{l}\text { Padrão 1: O gestor } \\
\text { competente em informação } \\
\text { determina a natureza e a } \\
\text { extensão da necessidade de } \\
\text { informação. }\end{array}$ & $\begin{array}{l}\text { - Reconhece e descreve os vários } \\
\text { aspectos de uma fonte, seus impactos e } \\
\text { valor para análise do ambiente da } \\
\text { organização, assim como as tendências e } \\
\text { impactos relacionados a pressupostos de } \\
\text { ordem cultural, geográfica ou histórica } \\
\text { e/ou atualidade da fonte de informação. }\end{array}$ \\
\hline & $\begin{array}{lrr}\text { Padrão 3: } & \text { O gestor } \\
\text { competente em informação } & \\
\text { avalia criticamente a } & \text { a } \\
\text { informação e suas fontes. }\end{array}$ & $\begin{array}{l}\text { - Compara a nova informação com o } \\
\text { conhecimento próprio e outras fontes } \\
\text { consideradas como autoridade no } \\
\text { assunto para conclusões. }\end{array}$ \\
\hline & $\begin{array}{l}\text { Padrão 4: } \text { O gestor } \\
\text { competente em informação, } \\
\text { individualmente ou como } \\
\text { membro de um grupo, usa a } \\
\text { informação com efetividade } \\
\text { para alcançar um } \\
\text { objetivo/obter um resultado. }\end{array}$ & $\begin{array}{l}\text { - Organiza a informação, utilizando } \\
\text { esquemas ou estruturas diversas; } \\
\text { - Comunica os resultados de projetos com } \\
\text { efetividade. }\end{array}$ \\
\hline \multirow[t]{2}{*}{$\begin{array}{c}\text { 4) Compartilhamento e } \\
\text { distribuição do } \\
\text { conhecimento: etapa que } \\
\text { coloca como condição da } \\
\text { empresa, o } \\
\text { desenvolvimento de } \\
\text { práticas que transforme } \\
\text { informações ou } \\
\text { experiências isoladas dos } \\
\text { funcionários em } \\
\text { conhecimento que todos } \\
\text { na organização possam } \\
\text { utilizar, por meio do } \\
\text { compartilhamento e } \\
\text { distribuição desse } \\
\text { conhecimento. }\end{array}$} & $\begin{array}{l}\text { Padrão 4: O gestor } \\
\text { competente em informação, } \\
\text { individualmente ou como } \\
\text { membro de um grupo, usa a } \\
\text { informação com efetividade } \\
\text { para alcançar um } \\
\text { objetivo/obter um resultado. }\end{array}$ & $\begin{array}{l}\text { - Comunica os resultados de projetos com } \\
\text { efetividade. }\end{array}$ \\
\hline & $\begin{array}{llr}\text { Padrão 5: } & \text { g gestor } \\
\text { competente em informação } \\
\text { compreende as questões } \\
\text { econômicas, legais e sociais da } \\
\text { ambiência do uso da } \\
\text { informação e acessa e usa a } \\
\text { informação } & \text { ética } & \text { e } \\
\text { legalmente. } & & \\
\end{array}$ & $\begin{array}{l}\text { - Demonstra compreensão sobre as } \\
\text { questões legais, éticas e socioeconômicas } \\
\text { que envolvem a informação, a } \\
\text { comunicação e a tecnologia. }\end{array}$ \\
\hline & & \\
\hline
\end{tabular}

Perspectivas em Gestão \& Conhecimento, João Pessoa, v. 8, número especial, p. 183-199, out. 2018. 


\begin{tabular}{|c|c|c|}
\hline \multirow{3}{*}{$\begin{array}{c}\text { 5) Utilização do } \\
\text { conhecimento: consiste } \\
\text { na prática de assegurar } \\
\text { que os funcionários } \\
\text { utilizem o conhecimento } \\
\text { nas atividades diárias da } \\
\text { empresa. }\end{array}$} & $\begin{array}{lrr}\text { Padrão 3: } & \text { O gestor } \\
\text { competente em informação } \\
\text { avalia criticamente a } \\
\text { informação e suas fontes. }\end{array}$ & $\begin{array}{l}\text { - Compara a nova informação com o } \\
\text { conhecimento próprio e outras fontes } \\
\text { consideradas como autoridade no } \\
\text { assunto para conclusões. }\end{array}$ \\
\hline & $\begin{array}{l}\text { Padrão 4: } \\
\text { competente em informação, } \\
\text { individualmente ou como } \\
\text { membro de um grupo, usa a } \\
\text { informação com efetividade } \\
\text { para alcançar um } \\
\text { objetivo/obter um resultado. }\end{array}$ & $\begin{array}{l}\text { - Comunica os resultados de projetos com } \\
\text { efetividade. }\end{array}$ \\
\hline & $\begin{array}{l}\text { Padrão 5: } \\
\text { competente em informação } \\
\text { compreende as questões } \\
\text { econômicas, legais e sociais da } \\
\text { ambiência do uso da } \\
\text { informação e acessa e usa a } \\
\text { informação } \\
\text { legalmente. ética }\end{array}$ & $\begin{array}{l}\text { - Demonstra compreensão sobre as } \\
\text { questões legais, éticas e socioeconômicas } \\
\text { que envolvem a informação, a } \\
\text { comunicação e a tecnologia. }\end{array}$ \\
\hline \multirow{3}{*}{$\begin{array}{c}\text { 6) Retenção de } \\
\text { conhecimento: relativo } \\
\text { ao processo de estruturar } \\
\text { e gerenciar o } \\
\text { conhecimento, com o } \\
\text { intuito de poder utilizá-lo } \\
\text { futuramente e evitar sua } \\
\text { perda da memória } \\
\text { organizacional. }\end{array}$} & $\begin{array}{l}\text { Padrão 2: } 0 \text { gestor } \\
\text { competente em } \\
\text { acessa informação } \\
\text { necessária com efetividade. }\end{array}$ & $\begin{array}{l}\text { - Registra todas as informações com as } \\
\text { citações pertinentes para futura } \\
\text { referenciação bibliográfica. }\end{array}$ \\
\hline & $\begin{array}{l}\text { Padrão 4: } \\
\text { competente em informação, } \\
\text { individualmente ou como } \\
\text { membro de um grupo, usa a } \\
\text { informação com efetividade } \\
\text { para alcançar um } \\
\text { objetivo/obter um resultado. }\end{array}$ & $\begin{array}{l}\text { - Comunica os resultados de projetos com } \\
\text { efetividade. }\end{array}$ \\
\hline & $\begin{array}{l}\text { Padrão 5: O gestor } \\
\text { competente em informação } \\
\text { compreende as questões } \\
\text { econômicas, legais e sociais da } \\
\text { ambiência do uso da } \\
\text { informação e acessa e usa a } \\
\text { informação ética } \\
\text { legalmente. }\end{array}$ & $\begin{array}{l}\text { - Demonstra compreensão sobre as } \\
\text { questões legais, éticas e socioeconômicas } \\
\text { que envolvem a informação, a } \\
\text { comunicação e a tecnologia; } \\
\text { - Demonstra conhecer as políticas } \\
\text { institucionais sobre o plágio e os direitos } \\
\text { autorais; } \\
\text { - Demonstra conhecimento do que é } \\
\text { plágio e não o usa em suas comunicações; } \\
\text { - Obtém permissão para copiar textos, } \\
\text { imagens ou sons em seu projeto final; } \\
\text { - Utiliza estilo e forma de linguagem de } \\
\text { redação apropriados, com a indicação } \\
\text { correta e consistente das fontes } \\
\text { consultadas. }\end{array}$ \\
\hline
\end{tabular}

Fonte: Elaborado pelas autoras (2018)

A transversalidade exposta no Quadro 3 é uma projeção que deve ser posta em experimentação e revisada constantemente. Demonstra, à priori, que cada etapa da GC possui uma interface plural em termos de Colnfo, visto que retrata uma variedade de capacidades, habilidades e atitudes dessa competência. Para a GC, a pluralidade dessa competência é necessária, pois representa "[...] a ativação de conexões, reflexões, avaliações, interpolações,

Perspectivas em Gestão \& Conhecimento, João Pessoa, v. 8, número especial, p. 183-199, out. 2018. 
de saberes múltiplos, de agir e intervir de maneira prática, a partir de aprendizados, para a compreensão e intervenção crítica de uma situação" (SANTOS, 2017, p. 77).

O Padrão 1 de Colnfo é necessário à GC para reconhecer as demandas de necessidades de conhecimento, uma vez que essa ação requer a identificação e diferenciação de tipos de informação para a construção de conhecimento de acordo com as áreas de interesse da organização. Esse padrão permite ao gestor determinar sua necessidade de informação, visto que, somente com essa consciência será capaz de reconhecer o ambiente organizacional no qual está inserido e qual tipo de informação será necessária para que consiga construir um conhecimento válido e de qualidade. Ao mesmo tempo, o gestor necessita compreender a relevância do processo de identificação do conhecimento, para que perceba o quanto se torna importante definir primeiramente as informações necessárias para cada momento.

O Padrão 2 de Colnfo é imprescindível à GC na medida em que oferece as condições ideais para constatar lacunas na recuperação da informação no que se refere à abrangência e conteúdo do conhecimento necessário a tomada de decisões, resoluções de problemas e vantagem competitiva. Embasa a captação de conhecimento gerado por diferentes pessoas da organização.

O Padrão 3 de Colnfo se faz necessário à GC para mapear e reconhecer fluxos informacionais, pois é a partir da análise de informações oriundas de fontes confiáveis que é possível traçar estratégias de conhecimento significativo para tomada de decisões e resolução de problemas.

Os Padrões 4 e 5 de Colnfo são elementares à GC, posto que criam as condições para que os gestores proporcionem comunicação informacional de maneira eficiente utilizando as TIC, como também otimizam a criação de espaços criativos por meio do diálogo e socialização do conhecimento significativo entre todos.

Ressalta-se que o gestor competente em informação possui a criticidade sobre suas ações visto que está comprometido e consciente sobre sua responsabilidade ao buscar, recuperar, avaliar, compartilhar e comunicar as informações para a construção e socialização de conhecimento significativo no que se refere às demandas e características do ambiente organizacional que está atuando.

\section{CONSIDERAÇÕES FINAIS}

As irregularidades do mercado financeiro, novidades, fundamentos, diálogos e inovações decorrentes da globalização, da Sociedade da Informação e do Conhecimento e da inovação científico-tecnológica têm feito com que os processos de trabalho, baseados em conhecimentos teóricos e práticos profissionais, requeiram dos indivíduos competências intelectuais e informacionais associadas ao raciocínio lógico, à solução de problemas, à interpretação de dados e à sondagem de informações coerentes para a compreensão do contexto, intervenção da realidade e gestão do conhecimento.

Nesse contexto, o gestor se torna consciente de que, a partir da internalização da Colnfo, tem condições para construir seu conhecimento, visto que essa competência desenvolve uma postura investigativa, analítica, crítica, criativa e ética em relação ao uso inteligente da informação. $O$ gestor também reconhece que a Colnfo o torna capaz de gerar e socializar conhecimento significativo, de maneira holística à organização, como um fator de vantagem competitiva.

A proposta de transversalidade da pesquisa não teve a intenção de esgotar teoricamente o objeto em foco, recomendando-se que haja continuidade nos estudos no âmbito da Ciência da Informação a fim de que se elucide melhor essa discussão sob a ótica de novos enfoques e perspectivas, seja na práxis teórica ou empírica.

Perspectivas em Gestão \& Conhecimento, João Pessoa, v. 8, número especial, p. 183-199, out. 2018. 


\section{REFERÊNCIAS}

ALMEIDA FILHO, N. Transdisciplinaridade e Saúde Coletiva. Ciência \& Saúde Coletiva, Rio de Janeiro, $\quad$ v. $\quad 2, \quad$ n.1, $1997 . \quad$ Disponível em: http://www.scielo.br/scielo.php?script=sci arttext\&pid=\$1413-81231997000100005. Acesso em: 10 jun. 2018.

BELLUZZO, R. C. B.; KOBAYASHI, M. C. M.; FERES, G. G. Information literacy: um indicador de competência para a formação de professores na sociedade do conhecimento. Educação Temática Digital, Campinas, v. 6, n. 1, 81-89, 2004.

BELLUZZO, R. C. B. Construção de mapas: desenvolvendo competências em informação e comunicação. 2. ed. Bauru: Cá Entre Nós, 2007.

BENITO MORALES, Félix. Nuevas necessidades, nuevas habilidades, fundamentos de la alfabetización em información. In: GOMÉZ HÉRNADEZ, J. A. et al. (Orgs.). Estrategias y modelos para enseñar a usar la información. Murcia: KR, 2000.

BUKOWITZ, W.R.; WILLIAMS, R. L. Manual de gestão do conhecimento: ferramentas e técnicas que criam valor para a empresa. Porto Alegre: Bookman Editora, 2002.

CATTS, R.; LAU, J. Towards information literacy indicators. UNESCO: Paris, 2008.

CRAWFORD, R. Na era do capital humano. São Paulo: Atlas, 1994.

COELHO, M. M. Competência informacional no ambiente de trabalho: percepção do bibliotecário de órgão público. Liinc em Revista, Rio de Janeiro, v. 7, n. 1, p. 170-196, 2011.

DAVENPORT, T. H.; PRUSAK, L. Conhecimento empresarial: como as organizações gerenciam o seu capital intelectual. Rio de Janeiro: Campus, 1998.

DIAS, M. M. K.; BELLUZZO, R. C. B. Gestão da informação em ciência e tecnologia sob a ótica do cliente. Bauru: Edusc, 2003.

DRUCKER, P. Desafios gerenciais para o século XXI. São Paulo: Pioneira, 1999.

GIL, A. C. Métodos e técnicas de pesquisa social. 6. ed. São Paulo: Atlas, 2012.

HOFFMANN, W. A. M. Gestão do conhecimento: desafios de aprender. São Carlos: Compacta, 2009.

MAIA, C. Casa de ferreiro, espeto de pau: a gestão do conhecimento em empresas produtoras de conhecimento. In: TERRA, J. C. C. Gestão do conhecimento e e-learning na prática. Rio de Janeiro: Elsevier, 2003. p. 4-18.

MALHOTRA, Y. Knowledge management and business model innovation. Oakland: Idea Group Publishing, 2001.

Perspectivas em Gestão \& Conhecimento, João Pessoa, v. 8, número especial, p. 183-199, out. 2018. 
MARCONI, M. A.; LAKATOS, E. M. Técnicas de pesquisa: planejamento e execução de pesquisas, amostras e técnicas de pesquisa, elaboração, análise e interpretação de dados. 7 . ed. São Paulo: Atlas, 2008.

NONAKA, I.; TAKEUCHI, H. Criação de conhecimento na empresa: como as empresas japonesas geram a dinâmica da inovação. Rio de Janeiro: Campus, 1997.

PIRES, M.F.C. Multidisciplinaridade, interdisciplinaridade e transdisciplinaridade no ensino. Interface - Comunicação, Saúde, Educação, n.2, fev. 1998.

PROBST, G.; RAUB, S.; ROMHARDT, K. Gestão do conhecimento: os elementos constitutivos do sucesso. Bookman: Porto Alegre, 2002.

SABBAG, P.Y. Espirais do conhecimento: ativando indivíduos, grupos e organizações. São Paulo: Saraiva, 2007.

SANTOS, C. A. Competência em Informação na formação básica dos estudantes da educação profissional e tecnológica. 2017. 287f. Tese (Doutorado em Ciência da Informação) Universidade Estadual Paulista, Marília, 2017. Disponível em: http://www.marilia.unesp.br/Home/PosGraduacao/Cienciadalnformacao/Dissertacoes/sant s ca do.pdf. Acesso em: 16 jun. 2018.

SETZER, V. W. Os meios eletrônicos e a educação: uma visão alternativa. São Paulo: Editora Escrituras, 2001.

SILVA, J. L. C. A informação na ciência da informação como perspectivismo pluri/multi, inter e transdisciplinar: do princípio quantitativo pluridisciplinar à unificação transdisciplinar. In: Encontro Nacional de Pesquisa em Ciência da Informação - ENANCIB, 18, 2017, Marília, SP. Anais... Marília: UNESP, 2017. Disponível em: http://enancib.marilia.unesp.br/index.php/xviiienancib/ENANCIB/paper/viewFile/284/946. Acesso em: 27 jun. 2018.

SOFFNER, R. K. Gestão do conhecimento e mudança organizacional. In: SILVA FILHO, C. F.; SILVA, L. F. (Org.). Tecnologia de informação e gestão do conhecimento. Campinas: Alínea, 2005. p. 70-77.

STOLLENWERK, M. F. L. Gestão do conhecimento: conceitos e modelos. In: TARAPANOFF, K. (Org.). Inteligência organizacional e competitiva. Brasília: Editora UNB, 2001.

TERRA, J. C. C. Gestão do conhecimento: aspectos conceituais e estudo exploratório sobre as práticas de empresas brasileiras. In: FLEURY, M. T. L.; OLIVEIRA JÚNIOR, M. M. Gestão estratégica do conhecimento: integrando aprendizagem, conhecimento e competências. São Paulo: Atlas, 2001.

VALENTIM, M. L. P. Gestão da informação e gestão do conhecimento: especificidades e convergências. Londrina: Infohome, 2004 (Artigo em Web). Disponível em: http://www.ofaj.com.br/colunas conteudo.php?cod=88. Acesso em: 12 jun. 2017.

Perspectivas em Gestão \& Conhecimento, João Pessoa, v. 8, número especial, p. 183-199, out. 2018. 
WENGER, E. Communities of practice: Learning, meaning and identity. Cambridge: Cambridge University Press, 1998.

Artigo recebido em 09/10/2018 e aceito para publicação em 29/10/2018 